\title{
Factors associated with life satisfaction among married women in rural China: a cross-sectional study based on large-scale samples
}

This article was published in the following Dove Press journal:

Psychology Research and Behavior Management

\author{
Hao Huang' \\ Siqi Liu' \\ Aditi Sharma ${ }^{2}$ \\ Futing Zou' \\ Fangqiong Tian' \\ Hui Wu' \\ 'Department of Social Medicine, \\ School of Public Health, China \\ Medical University, Shenyang, Liaoning \\ Province, China; ${ }^{2}$ Department of \\ Public Health Science, College \\ of Medicine, Pennsylvania State \\ University, Hershey, PA, USA
}

Purpose: The living environment in rural China may predispose individuals there to low life satisfaction (LS). This study aims to evaluate factors that affect LS among married women in rural China.

Materials and methods: This cross-sectional study was conducted in rural Liaoning Province in China, in 2015. Out of 3,900 married women, 3,385 (86.8\%) completed a questionnaire survey. LS was assessed using the Satisfaction with Life Scale (SWLS), with 35 as the maximal possible score. Stress (quantified by the Perceived Stress Scale [PSS]), resilience (assessed by the Ego-Resiliency Scale [ERS]), and demographic and living/health conditions factors were collected through self-reported questionnaires. Hierarchical multiple regression and structural equation modeling were used to explore the contributing and mediating factors related to LS. Results: The overall LS score was 18.94 \pm 4.96 . A younger age, lower monthly income, presence of chronic diseases, left-behind status, and sense of marriage insecurity were negatively associated with LS. Perceived stress was a strong predictor of LS, as it explained $19.7 \%$ of the variance. Higher levels of resilience were related to higher levels of LS, explaining $15.4 \%$ of the variance. Resilience partially mediated the relationship between stress and LS for rural residents in China. Conclusion: Overall, married women living in rural China experienced a relatively low level of LS. The construction of additional recreational facilities, provision of convenient access to medical information, facilitation of communication between couples, reduction of stress, and development of resilience could all be beneficial intervention strategies to improve LS for these rural residents.

Keywords: rural women, left-behind, life satisfaction, stress, resilience

\section{Introduction}

Life satisfaction (LS) is the perceived assessment of whether one is content with one's life. ${ }^{1}$ It is well accepted that a low level of LS could directly and negatively influence the experience of one's life course, health, work performance, and social development. . $^{2,3}$ Since 2010, UK, USA, and France have attached increased importance to LS to help promote a better quality of life. ${ }^{4}$ More recently, China has also begun research in LS. In 2016, the government of China conducted a national survey on LS and reported its increase among residents in comparison to the previous survey in $2015 .{ }^{5}$ However, studies on the factors related to LS among rural women are still few in number, which necessitates the present study.

China is one of the largest agricultural countries, where 603 million people live in rural areas. ${ }^{6}$ Among those individuals, owing to the massive migration of young rural residents to the cities, most rural women left are married, the number of which is esti-
Department of Social Medicine, School of Public Health, China Medical University, No. 77 Puhe Road, Shenyang North New Area, Shenyang 110122 , China

Tel +86 I3840I 39926

Email hwu@cmu.edu.cn 
mated to be around 200 million. Married women play crucial roles as an indispensable labor force and primary care givers to family members in rural areas. ${ }^{7}$ However, due to differences between urban and rural China, some noteworthy factors in rural areas may have a significant impact on the LS of married rural women. For example, Jia et al reported that left-behind women had poor living conditions, posing a substantial impact on their LS. ${ }^{8}$ The term "left-behind" refers to the situation in which married women stay at home in rural areas while their husbands migrate to other cities in search of jobs, and thus live away from home for over 6 months at a time. ${ }^{9}$ Unexpectedly, the population of left-behind women in rural China was reported to be more than 50 million in $2011 .{ }^{10}$ Previous studies have shown that left-behind women might be predisposed to more physical disorders, an increased distress associated with loneliness, and the rising feeling of marriage insecurity, which might adversely affect their LS. ${ }^{11-13}$ Moreover, because of the traditional preference for a male child in China, some rural families may want additional children until the birth of a baby boy. ${ }^{14}$ One study by $\mathrm{Wu}$ and $\mathrm{Li}$ indicated that the number of children in a family could affect the health status of parents, especially the mother. ${ }^{15}$ Therefore, the number of children in a family may also potentially impact the LS of married women in rural China.

There has also been an increasing number of studies on the role of LS in relation to stress. Stress can be defined as the experience of individuals who are worried or uncomfortable about something and cannot cope with or control the situation. ${ }^{16}$ Moksnes and Haugan reported that stress was significantly and inversely associated with LS. ${ }^{17}$ Jain et al also reported a negative relationship between work-related stress and LS. ${ }^{18}$ Notably, married women living in rural China may be exposed to enormous levels of stress due to insufficient income, heavy physical labor, spiritual emptiness, and a lack of recreational facilities. ${ }^{19-21}$ Sustained stress can trigger psychosomatic responses and engender unremitting negative emotions, which can lead to depression, anxiety, and even suicidal ideation that directly affects LS. ${ }^{22-25}$

Researchers focusing on LS have also paid attention to positive psychological resources, such as resilience. Resilience is usually considered a capability that can be developed to rebound or bounce back from tragedy, frustration, and failure, or even positive events. ${ }^{26,27}$ Previous studies have reported that resilience has a positive effect on LS, and the quality of life, as resilient individuals were related to high levels of hope and optimism in enjoying a better life. ${ }^{28,29}$ Evidence has also revealed that resilience is negatively associated with perceived stress. ${ }^{30,31}$ According to the resiliency theory, it provides a bio-psycho-social framework, which indicates that the cumulative effects of environmental and individual-level factors can pose risks to the individual's psychological resilience. ${ }^{32}$ Thus, resilience can be affected by cumulative stressors. Furthermore, Shi et al reported that resilience could function as a mediator in the association between perceived stress and LS among medical students. ${ }^{33}$ However, to our knowledge, few studies have discussed the associations among resilience, stress, and LS with a focus on married rural women. Thus, to evaluate the factors affecting LS that could be adjusted to further improve the LS of married women in rural China, we hypothesize the following:

1. Demographic and living/health condition factors such as age, education, monthly income, left-behind status, and the number of children in a family may be significantly associated with LS among married women in rural China;

2. After adjusting for demographic and living/health conditions factors, perceived stress would still be an important factor for LS among married women in rural China;

3. Resilience can act as a mediator in the association between perceived stress and LS among married women in rural China.

\section{Materials and methods}

\section{Ethics statement}

The study protocol was in accordance with ethical standards and was approved by the ethics committee of China Medical University. Written informed consent was obtained from each participant. Information collected from all participants was kept confidential and anonymous.

\section{Study design and data collection}

A cross-sectional study was carried out in Tieling, Liaoning Province, during 2015. Based on the geographic division, Tieling city consists of five geographic regions (eastern, western, southern, northern, and central). Two townships were randomly selected in each region; three villages were randomly selected from each chosen township, with a total of 3,900 married women being randomly selected from those villages. After obtaining written informed consent, the self-administered questionnaires were distributed to each participant. The responses were collected from 3,385 of participants, yielding an effective response rate of $86.8 \%$.

\section{Demographic and living/health factors}

Demographic factors in the current study included age (classified as $<45,45-60$, and $>60$ years); education 
(divided into primary school and lower, junior high school, and senior high school and higher); and monthly income (divided into $<1,000 \mathrm{RMB}$ [around \$150], 1,000-3,000 $\mathrm{RMB}$, and $>3,000 \mathrm{RMB})$. Four living and health condition factors were also assessed including the presence of chronic disease, left-behind status, sense of marriage security, and number of children in a family. Chronic diseases were assessed by the question "Have you been diagnosed with chronic diseases? (such as hypertension, diabetes, chronic obstructive pulmonary disease, tumors, or other chronic diseases)" with the options: yes or no. Left-behind status was determined based on the length of time the husbands of the participants worked outside the home. A married woman was considered left-behind if her husband worked at a location that demanded living separately from his wife for more than 6 months in a given year. Sense of marriage security was assessed by the question "Do you think your marriage is secure?" The answers were divided into very secure, secure, or insecure. The number of children in a family was classified as 0,1 , and $\geq 2$.

\section{Measurement of LS}

An international measure - the Satisfaction with Life Scale (SWLS) developed by Diener et al - was used to assess LS. ${ }^{34}$ This scale consists of five items (eg, In most ways my life is close to my ideal.) with each item using a 7-point Likert scale from 1 (strongly disagree) to 7 (strongly agree). The answers are then summed up to create a total score from 5 to 35 , with higher scores indicating higher levels of LS. Previous research has demonstrated satisfactory validity and reliability of the scale among Chinese groups. ${ }^{35}$ In the present study, the Cronbach's alpha coefficient of the SWLS was 0.863. The confirmatory factor analysis confirmed that SWLS had satisfactory validity (the root mean square error of approximation $[\mathrm{RMSEA}]=0.080$; the comparative fit index $[\mathrm{CFI}]=0.995$; the goodness-of-fit index $[\mathrm{GFI}]=0.995$; the adjusted goodness-offit index $[\mathrm{AGFI}]=0.961$; the Tucker-Lewis index $[\mathrm{TLI}]=0.976$; and the normed fit index $[\mathrm{NFI}]=0.995$ ).

\section{Measurement of stress}

Stress was measured by the Perceived Stress Scale (PSS), developed by Cohen et al, which has been widely used worldwide to assess perceived stress. ${ }^{36}$ The PSS consists of ten items that assess one's feelings in the previous month (eg, In the last month, how often have you felt confident about your ability to handle your personal problems?). Items were scored on a 5-point Likert scale, ranging from 0 (never) to 4 (very often). The overall score ranges from 0 to 40 and higher scores indicate higher levels of stress. The scale has generally been used among Chinese people and has demonstrated considerable reliability and validity. ${ }^{37}$ In this study, the Cronbach's alpha value for the PSS was 0.711. The confirmatory factor analysis confirmed that the PSS had satisfactory validity $(\mathrm{RMSEA}=0.078, \mathrm{CFI}=0.930, \mathrm{GFI}=0.968$, AGFI $=0.934$, TLI $=0.927$, and $\mathrm{NFI}=0.884$ ).

\section{Measurement of resilience}

Resilience was assessed by the Chinese version of EgoResiliency Scale (ERS) originally developed by Block and Kremen, which is considered as one of the most effective tools to assess resilience. ${ }^{38}$ It comprises 14 items (eg, I am generous with my friends.) rated on a 4-point Likert-type scale ranging from 1 (does not apply at all) to 4 (applies very strongly). Each item is added to provide an overall score and higher scores indicate higher levels of resilience. The Chinese version of the ERS reportedly has good reliability and validity. ${ }^{39}$ Cronbach's alpha coefficient of the scale was 0.884 in this study. The confirmatory factor analysis confirmed that ERS had a satisfactory validity $(\mathrm{RMSEA}=0.079, \mathrm{CFI}=0.924$, $\mathrm{GFI}=0.944$, AGFI=0.910, TLI=0.921, and $\mathrm{NFI}=0.894$ ).

\section{Statistical analyses}

The LS scores (mean \pm SE) in different groups of demographic and living/health conditions factors were tested by the independent samples $t$-test or one-way ANOVA. Pearson's correlation analysis was used to assess correlations among continuous variables. Confirmatory factor analysis was applied to test the validity of the scales. Hierarchical regression analysis was used to explore the mediating effect of resilience in the association between stress and LS. All variables related to $\mathrm{LS}$ in univariate analysis $(P<0.05)$ were entered into the hierarchical regression analysis. In block 1, demographic variables (age, monthly income, left-behind status, presence of chronic diseases, and sense of marriage security) were added as covariates. In block 2 , stress was added as an independent variable. In block 3 , resilience was added as a mediating variable. Variance Inflation Factor (VIF) was used to estimate whether regression coefficient increased because of collinearity. In present study, VIF values $<10$, which was considered that multicollinearity was not an issue in the estimate. Standardized estimates $(\beta), F$, adjusted $R^{2}$, and $R^{2}$-change $\left(\triangle R^{2}\right)$ for each block were provided. To explore the potential mediating role of resilience (Figure 1), in the first step, the aim was to test the effect of stress on LS (the c path) after adjusting for covariates; in the second step, the aim was to examine the 
Step

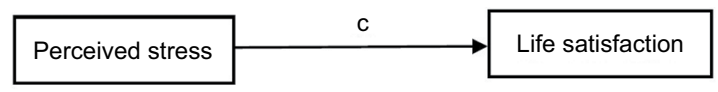

Step 2

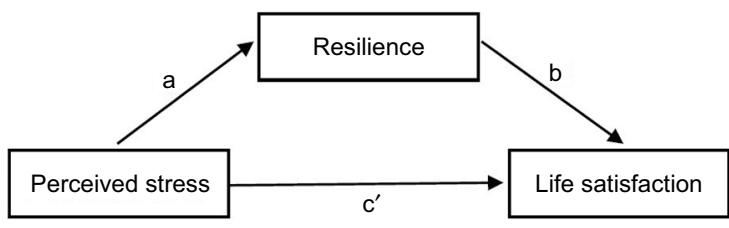

Figure I Theoretical model of the mediation of resilience on the association between perceived stress and LS.

Note: c: associations of perceived stress with LS; a: associations of perceived stress with resilience; $b$ : association between resilience and LS after controlling for the covariates; and c': associations of perceived stress with LS after adding resilience as a mediator.

Abbreviation: LS, life satisfaction.

mediation of resilience. If the effect of stress on LS ( $c^{\prime}$ path coefficient) in the second step was either not significant or smaller than the $\mathrm{c}$ path coefficient in the first step, existence of the mediation of resilience was considered a possibility. Structural equation modeling was used to examine resilience as a potential mediator in the association between stress and LS. ${ }^{40}$ To determine whether the hypothesized model fits the data well, criteria included the following: 1) RMSEA $<0.08$; 2) CFI $>0.90$; 3) GFI $>0.90$; 4) AGFI $>0.80$; 5) TLI $>0.90$; and 6) NFI $>0.80$.

All analyses were carried out using 20.0 SPSS and 17.0 AMOS statistical software for Windows. All statistical tests were two-tailed, and the level of significance was set at $P<0.05$.

\section{Results}

\section{Demographic characteristics and living/ health conditions of subjects}

The demographic characteristics and living/health conditions among the rural married women and the distributions of LS are shown in Table 1. The average age of the participants was $46.64 \pm 10.10$ (mean \pm SD) years and the average LS score of the participants was $18.94 \pm 4.96$. Women older than 60 years and having higher monthly income were more likely to have higher levels of LS, in comparison to other groups. Among the 3,385 rural women, 1,071 (31.6\%) were left-behind. In comparison to those left-behind, non-left-behind women had significantly higher levels of LS $(P<0.05)$. Similarly, women without chronic diseases showed higher scores of LS $(P<0.05)$, in comparison to women with chronic diseases. Regarding a sense of marriage security, the LS scores of those who thought their marriage was very safe were higher than those of other groups. In addition, in comparison to either more than two children or no children, the women with one child had higher levels of LS. However, no differences in LS were observed among rural married women with different levels of education $(P>0.05)$.

\section{Correlations among study variables}

The results of Pearson correlation analysis are shown in Table 2. Age, stress, resilience, and LS were significantly correlated with each other in the expected direction. Stress was negatively correlated with resilience $(r=-0.229, P<0.01)$ and LS ( $r=-0.471, P<0.01)$, and resilience was positively correlated with LS $(r=0.502, P<0.01)$. Given the potential effects of demographic (such as age) and living/health condition factors (such as left-behind status), stress, resilience, and LS, along with those covariates were all included in the subsequent analyses.

\section{Mediating role of resilience in the association between stress and LS}

As shown in Table 3, the hierarchical regression analysis was used to explore the contributing and mediating factors associated with LS. In step 1, we found that increasing age, higher monthly income, and a higher sense of marriage security were associated with higher LS scores, whereas left-behind status and the presence of chronic diseases were negatively associated with LS. However, no association was observed between the number of children in a family and LS. In step 2 , stress was found to be significantly and negatively related to LS ( $\beta=-0.449, P<0.01$ ), accounting for $19.7 \%$ of the variance. In step 3 , resilience was found to be positively associated with LS, accounting for $15.4 \%$ of the variance ( $\beta=0.407, P<0.01)$. Moreover, the negative effect of stress on LS (0.361) in step 3 was smaller than 0.449 in step 2, indicating the possible existence of mediation of resilience in the relationship between stress and LS.

Structural equation modeling was applied to examine whether the resilience mediated the association of stress with LS. Standardized path coefficients are displayed in Figure 2; all the path coefficients were statistically significant at the level of $P<0.01$. Fit indices of the hypothesized model showed an acceptable data model fit (RMSEA $=0.043$, $\mathrm{CFI}=0.927, \mathrm{GFI}=0.943$, AGFI $=0.917$, TLI $=0.927$, and $\mathrm{NFI}=0.904$ ), which confirmed that resilience significantly and partially mediated the association between stress and LS. The standardized direct effect of perceived stress on the LS scores was -0.36 ; the standardized indirect effect of perceived stress through resilience on LS was -0.09 . The 
Table I Mean scores of LS according to demographic characteristics and living/health conditions of participants. $(n=3,385)$

\begin{tabular}{|c|c|c|c|}
\hline Variables & n (\%) & LS (mean \pm SE) & $P$-value \\
\hline Age (years) & & & $<0.001$ \\
\hline$<45$ & $1,342(39.6)$ & $18.54 \pm 0.14$ & \\
\hline $45-60$ & $\mathrm{I}, 638(48.4)$ & $19.13 \pm 0.12$ & \\
\hline$>60$ & $405(12.0)$ & $19.51 \pm 0.22$ & \\
\hline Education background & & & 0.640 \\
\hline Primary school and lower & $969(28.6)$ & $19.03 \pm 0.16$ & \\
\hline Junior high School & $2,120(62.6)$ & $18.93 \pm 0.11$ & \\
\hline Senior high school and above & $296(8.8)$ & $18.72 \pm 0.28$ & \\
\hline Monthly income (RMB) & & & $<0.001$ \\
\hline$<1,000$ & $631(18.6)$ & $17.76 \pm 0.23$ & \\
\hline $1,000-3,000$ & $1,859(54.9)$ & $18.96 \pm 0.11$ & \\
\hline$>3,000$ & $895(26.5)$ & $19.74 \pm 0.15$ & \\
\hline Chronic disease & & & $<0.001$ \\
\hline No & $\mathrm{I}, 410(41.7)$ & $19.26 \pm 0.11$ & \\
\hline Yes & $1,975(58.3)$ & $|8.7| \pm 0.13$ & \\
\hline Left-behind situation & & & $<0.001$ \\
\hline No & $2,314(68.4)$ & $19.15 \pm 0.10$ & \\
\hline Yes & I,07| (3I.6) & $18.50 \pm 0.16$ & \\
\hline Sense of marriage security & & & $<0.001$ \\
\hline Insecure & $397(11.7)$ & $16.92 \pm 0.28$ & \\
\hline Secure & $\mathrm{I}, 499(44.3)$ & $18.95 \pm 0.12$ & \\
\hline Very secure & $\mathrm{I}, 489(44.0)$ & $19.47 \pm 0.12$ & \\
\hline Number of children & & & 0.015 \\
\hline 0 & $129(3.8)$ & $18.22 \pm 0.47$ & \\
\hline 1 & I,987 (58.7) & $19.13 \pm 0.11$ & \\
\hline$\geq 2$ & $1,269(37.5)$ & $18.71 \pm 0.14$ & \\
\hline
\end{tabular}

Abbreviations: LS, life satisfaction; SE, standard error.

Table 2 Correlations of continuous variables

\begin{tabular}{|l|l|l|l|}
\hline Variables & LS & Stress & Resilience \\
\hline LS & $\mathrm{I}$ & & \\
Stress & $-0.47 \mathrm{I}^{* *}$ & $\mathrm{I}$ & \\
Resilience & $0.502^{* *}$ & $-0.229^{* *}$ & $\mathrm{I}$ \\
\hline
\end{tabular}

Note: $* * P<0.01$ (two-tailed).

Abbreviation: LS, life satisfaction.

proportion of the mediating effect of resilience was $20.0 \%$ $(0.09 /(0.09+0.36) \times 100 \%)$.

\section{Discussion}

This cross-sectional study explored the associations among resilience, stress, and LS in 3,385 rural women in China. Our results revealed that the average LS score of married women in rural China is $18.94 \pm 4.96$, which is lower than that of women in urban China (19.95 \pm 5.58$)$, urban residents in the

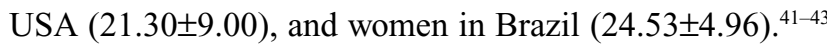
This discrepancy may stem from the different languages and survey administration used. However, it highlights the urgency with which the factors associated with LS should be identified, so that interventions can be made to meet the challenges of undesired LS within this population.

Our research focused on demographic and living/health condition factors as hypothetical predictors of LS. We found that age, monthly income, and a sense of marriage security were positively associated with LS, whereas left-behind status and the presence of chronic diseases were negatively related to LS. Unexpectedly, increasing age was associated with increased LS, which is inconsistent with the findings of other studies. ${ }^{44,45}$ One possible reason for this finding could be that as married women grow older, their resources increasingly become depleted, and the levels of their expectations and goals begin to decline. ${ }^{46}$ The discrepancy between their current life status and life expectations decreases with age, which explains the positive relationship between age and LS. In terms of financial status, a relatively low monthly income indicates potentially insufficient funds to meet material and spiritual needs. Besides, the lower the income, the lower the social status of the individual might be, which can make a considerable difference in their LS. Regardless of age and income, $11.7 \%$ of rural married women were shown to feel 
Table 3 Hierarchical linear regression analysis results

\begin{tabular}{|c|c|c|c|}
\hline \multirow[b]{2}{*}{ Variable } & \multicolumn{3}{|l|}{ LS } \\
\hline & Block I ( $\beta)$ & Block $2(\beta)$ & Block $3(\beta)$ \\
\hline Block I & & & \\
\hline Age & $0.112^{* *}$ & $0.084^{* *}$ & $0.066^{* *}$ \\
\hline Monthly income & $0.137^{* *}$ & $0.112^{* *}$ & $0.092^{* *}$ \\
\hline Chronic disease & $-0.084^{* *}$ & $-0.065^{* *}$ & $-0.065^{* *}$ \\
\hline $\begin{array}{l}\text { Left-behind } \\
\text { situation }\end{array}$ & $-0.06 I^{* *}$ & $-0.048 * *$ & $-0.064 * *$ \\
\hline $\begin{array}{l}\text { Sense of } \\
\text { marriage } \\
\text { security }\end{array}$ & $0.158^{* *}$ & $0.112^{* *}$ & $0.07 I^{* *}$ \\
\hline $\begin{array}{l}\text { Number of } \\
\text { children in a } \\
\text { family }\end{array}$ & -0.026 & -0.002 & -0.004 \\
\hline Block 2 & & & \\
\hline Stress & & $-0.449 * *$ & $-0.36 I^{* *}$ \\
\hline Block 3 & & & \\
\hline Resilience & & & $0.407^{* *}$ \\
\hline$F$ & $33.843^{* *}$ & $164.349 * *$ & $291.343 * *$ \\
\hline Adjusted $R^{2}$ & 0.055 & 0.253 & 0.407 \\
\hline$\triangle R^{2}$ & 0.057 & 0.197 & 0.154 \\
\hline
\end{tabular}

Note: $* * P<0.01$ (two-tailed).

Abbreviation: LS, life satisfaction.

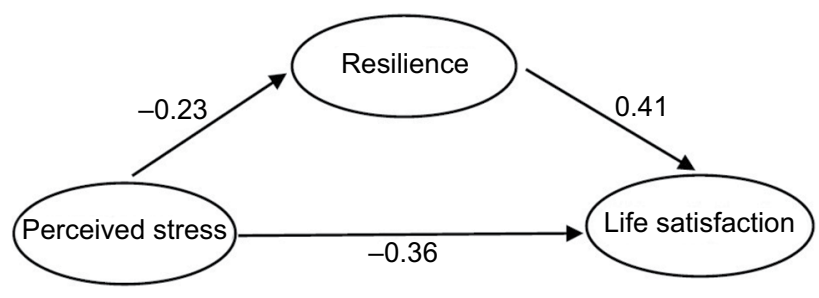

Figure 2 Structural equation model of the mediating role of resilience.

unsafe about their marriage, and their average LS score was much lower than those of other groups. When married rural women feel safe about their marriage, they are generally in good spirits. However, the feeling of marriage insecurity can result in loneliness and depression, which can evoke the experience of lower levels of LS. ${ }^{12}$

"Left-behind" wives are a subgroup that is worthy of specific attention. In our study, $31.6 \%$ of the married women were left-behind and experienced poorer LS. This might be attributed to the following reasons. Left-behind women, as a relatively vulnerable group, not only bear heavier burdens of family chores and farm work, supporting the elderly, and raising children independently but also lack personal and property safety, which predispose them to tremendous physical and psychological pressure. Furthermore, along with the deprivation of an active sex life, left-behind wives also tend to feel lonely and depressed leading to a sense of life dissatisfaction. Regarding chronic diseases, $58.3 \%$ of rural women were reportedly affected by some form of chronic disease. Chronic diseases such as hypertension, diabetes, and cancers will cause physical discomfort and pain, depression, anxiety, and other negative emotions, inevitably leading to a poorer quality of life.

Therefore, efforts need to be focused on improving the LS of married women living in rural China. For example, the construction of additional recreational facilities for young women and enhancement of the accessibility of health information in rural areas is necessary, so that rural women can learn to minimize their exposure to associated risk factors, and thereby facilitate the prevention of chronic diseases. ${ }^{47}$ Furthermore, material and economic support should be provided to left-behind women to support more frequent get-togethers between husband and wife. However, leftbehind wives can also learn to use Internet tools to simulate face-to-face conversation with their husbands to reduce the feeling of marriage insecurity. For non-left-behind wives, communities can provide more lectures or magazines about sexual health, which can help to improve their sexual LS and reduce their anxiety about marriage..$^{48}$

We found that the number of children in a family was not linearly related to LS, which is inconsistent with the previous research. ${ }^{15}$ Instead, we found that women without children and those with more than two children had lower LS scores than women with only one child. Thus, a nonlinear correlation may exist between them; however, these findings require further study.

Moreover, our results revealed that after adjusting for demographic and living/health conditions variables, perceived stress still accounted for $19.7 \%$ of the variance in LS. This finding supported our hypothesis that perceived stress might be a strong indicator of LS among married rural women. Perceived stress can be considered the result of a dynamic interaction between the external environment and the individual. ${ }^{49}$ Thus, the stressors of rural women may largely originate from themselves, family, or society, including diseases, negative life events, the responsibilities of taking care of children and the elderly, heavy farm work and household chores, and relatively poor social economic conditions with few entertainment facilities. These stressors affect the body through a series of psychosomatic responses, which alter normal functions through the endocrine and nervous systems. ${ }^{22}$ Cumulative stress can aggravate physical fatigue and will further produce negative emotions, thereby seriously affecting the subjective well-being of an individual's life. Accordingly, adequate measures must be taken 
to reduce perceived stress. Fundamentally, infrastructure, social welfare, and agricultural technology in rural China should be further improved. Besides, interventions such as seminars or broadcasts can help to promote the mastery of positive coping strategies among rural married women to effectively deal with stress and improve their LS. Moreover, a study by Gao et al indicated that "square dance" in urban China could effectively combat stress among middle-aged women. "Square dance" is a new style of social activity in China that is performed by residents who spontaneously dance in public squares for fitness purposes. Therefore, an appropriate "square dance" can be popularized in rural areas, as a coping strategy to help women deal with stress.

Finally, a partial mediation of resilience between perceived stress and LS was found, which is consistent with our hypothesis. The higher levels of stress felt by married rural women indicated lower levels of resilience. In fact, building resilience is usually considered a dynamic process, which indicates that resilience can be influenced by perceived stress. ${ }^{51}$ However, people with a high level of resilience can quickly rebound from a variety of adverse events and are rarely affected by negative emotions. ${ }^{33,52}$ The more resilient people are, the more confident and optimistic they will be. ${ }^{28,29}$ Thus, resilient participants enjoyed higher levels of LS. As resilience can be developed and managed, the resilience levels of married rural women could be enhanced by effective interventions. ${ }^{53} \mathrm{~A}$ previous study revealed that positive coping mechanisms had potential value in establishing resilience. ${ }^{54}$ Another study has demonstrated that individuals could increase resilience through regular engagement in a proactive personal reflective report. ${ }^{55}$ In addition, mindfulness training, as a form of cognitive training, can also be introduced to promote resilience. ${ }^{56}$ Given that high levels of perceived stress were reported among rural women in our study, trainings in appraising the stressors and finding meaning in the stressors could also play essential roles in building resilience. ${ }^{57}$ Targeted intervention strategies should be conducted in the future to develop the resilience of married rural women and thereby increase their LS.

Several limitations of the present study must be mentioned. First, we applied a cross-sectional design, which confined the ability to draw a causal conclusion among the variables investigated. Thus, findings from this study should be confirmed by further longitudinal studies. Second, all data used in this study were collected through self-reported questionnaires, which could introduce recall bias or response bias. Third, the participants were restricted to a rural area of Tieling city, in the northeastern part of China. Thus, caution should be taken when extrapolating the results to women living in other rural areas in China.

\section{Conclusion}

The present study revealed that married women living in rural China experienced a relatively low level of LS. Age, monthly income, chronic diseases, left-behind status, and a sense of marriage security were significant indicators of LS, and higher levels of stress were related to lower levels of LS. However, resilience is a positive psychological resource that can improve the LS among rural women, but can also be influenced by stressors. Therefore, efforts should be made to enhance resilience levels and reduce stress. Effective measures, such as building more recreational facilities, providing convenient access to medical information, facilitating communications between couples, promoting coping strategies, and increasing the resilience levels of rural women, should be considered to promote their LS.

\section{Acknowledgment}

The authors would like to thank the research assistants who undertook data collection and the participants for their selfless support of the study.

\section{Author contributions}

All authors contributed toward data analysis, drafting and critically revising the paper, gave final approval of the version to be published, and agree to be accountable for all aspects of the work.

\section{Disclosure}

The authors report no conflicts of interest in this work.

\section{References}

1. Lim HJ, Min DK, Thorpe L, Lee CH. Multidimensional construct of life satisfaction in older adults in Korea: a six-year follow-up study. BMC Geriatr. 2016;16(1):197.

2. La Placa V, Knight A. Well-being: its influence and local impact on public health. Public Health. 2014;128(1):38-42.

3. Yuan Q, Liu S, Tang S, Zhang D. Happy@Work: protocol for a webbased randomized controlled trial to improve mental well-being among an Asian working population. BMC Public Health. 2014;14:685.

4. Cheung F, Lucas RE. Assessing the validity of single-item life satisfaction measures: results from three large samples. Qual Life Res. 2014;23(10):2809-2818.

5. The State Council [webpage on the Internet]. The Life Satisfaction of Residents in China. Available from: http://www.gov.cn/xinwen/2016-11/23/content_5136300.htm. Accessed June 28, 2017.

6. National Bureau of Statistics of China [webpage on the Internet]. National data: population. Available from: http://data.stats.gov.cn/easyquery.htm?cn=C01\&zb=A0301\&sj=2015. Accessed September 2, 2018.

7. Hou F, Cerulli C, Wittink MN, Caine ED, Qiu P. Depression, social support and associated factors among women living in rural China: a cross-sectional study. BMC Womens Health. 2015;15:28. 
8. Jia DL, Cj L, Liu JH. Relation of social support to coping styles and life satisfaction in left-behind women. Chin Mental Health J. 2016;30:448-453.

9. Yi J, Zhong B, Yao S. Health-related quality of life and influencing factors among rural left-behind wives in Liuyang, China. BMC Womens Health. 2014;14:67.

10. Li Q. Vast Country, Vacant village. 2nd ed. Beijing: China Economic Press; 2015

11. Rożek-Piechura K, Ignasiak Z, Sławińska T, Piechura J, Ignasiak T. Respiratory function, physical activity and body composition in adult rural population. Ann Agric Environ Med. 2014;21(2):369-374.

12. Ben-Zur H. Loneliness, optimism, and well-being among married, divorced, and widowed individuals. $J$ Psychol. 2012;146(1-2): 23-36.

13. Zhong B, Yao SQ. Depressive symptoms and related influential factors in left-behind women in rural area. Chin J Clin Psychol. 2012;20(6): 839-841.

14. Zeng Y, Hesketh T. The effects of China's universal two-child policy. Lancet. 2016;388(10054):1930-1938.

15. Wu X, Li L. Family size and maternal health: evidence from the OneChild policy in China. J Popul Econ. 2012;25(4):1341-1364.

16. Carter JR, Goldstein DS. Sympathoneural and adrenomedullary responses to mental stress. Compr Physiol. 2015;5(1):119-146.

17. Moksnes UK, Haugan G. Stressor experience negatively affects life satisfaction in adolescents: the positive role of sense of coherence. Qual Life Res. 2015;24(10):2473-2481.

18. Jain AK, Giga SI, Cooper CL. Stress, health and well-being: the mediating role of employee and organizational commitment. Int $J$ Environ Res Public Health. 2013;10(10):4907-4924.

19. Xie Y, Zhou X. Income inequality in today's China. Proc Natl Acad Sci US A. 2014;111(19):6928-6933.

20. Matz CJ, Stieb DM, Brion O. Urban-rural differences in daily timeactivity patterns, occupational activity and housing characteristics. Environ Health. 2015;14:88.

21. Li LW, Liu J, Zhang Z, Xu H. Late-life depression in Rural China: do village infrastructure and availability of community resources matter? Int J Geriatr Psychiatry. 2015;30(7):729-736.

22. Cohen JI. Stress and mental health: a biobehavioral perspective. Issues Ment Health Nurs. 2000;21(2):185-202.

23. van der Waerden JE, Hoefnagels C, Hosman CM, Jansen MW. Defining subgroups of low socioeconomic status women at risk for depressive symptoms: the importance of perceived stress and cumulative risks. Int J Soc Psychiatry. 2014;60(8):772-782.

24. Fan LB, Blumenthal JA, Watkins LL, Sherwood A. Work and home stress: associations with anxiety and depression symptoms. Occup Med. 2015;65(2):110-116.

25. Currier D, Spittal MJ, Patton G, Pirkis J. Life stress and suicidal ideation in Australian men - cross-sectional analysis of the Australian longitudinal study on male health baseline data. BMC Public Health. 2016;16(Suppl 3):1031.

26. Luthans F, Youssef-Morgan CM, Avolio BJ. Psychological Capital: Developing the Human Competitive Edge. Oxford, UK: Oxford University Press; 2007.

27. Youssef-Morgan CM, Luthans F. Psychological capital and well-being. Stress Health. 2015;31(3):180-188.

28. Mautner E, Stern C, Deutsch M, et al. The impact of resilience on psychological outcomes in women after preeclampsia: an observational cohort study. Health Qual Life Outcomes. 2013;11(1):194.

29. Tugade MM, Fredrickson BL. Resilient individuals use positive emotions to bounce back from negative emotional experiences. $J$ Pers Soc Psychol. 2004;86(2):320-333.

30. Wilks SE, Croom B. Perceived stress and resilience in Alzheimer's disease caregivers: testing moderation and mediation models of social support. Aging Ment Health. 2008;12(3):357-365.
31. Costa ALS, Heitkemper MM, Alencar GP, Damiani LP, Silva RMD, Jarrett ME. Social support is a predictor of lower stress and higher quality of life and resilience in Brazilian patients with colorectal cancer. Cancer Nurs. 2017;40(5):352-360.

32. Greene RR. Human behavior theory. In: Greene RR, editor. Resiliency: An Integrated Approach to Practice, Policy, and Research. Washington, DC: NASW Press; 2002:1-27.

33. Shi M, Wang X, Bian Y, Wang L. The mediating role of resilience in the relationship between stress and life satisfaction among Chinese medical students: a cross-sectional study. BMC Med Educ. 2015;15:16.

34. Diener E, Emmons RA, Larsen RJ, Griffin S. The satisfaction with life scale. J Pers Assess. 1985;49(1):71-75.

35. Bai X, Wu C, Zheng R, Ren X. The psychometric evaluation of the satisfaction with life scale using a Nationally Representative Sample of China. J Happiness Stud. 2011;12(2):183-197.

36. Cohen S, Kamarck T, Mermelstein R. A global measure of perceived stress. J Health Soc Behav. 1983;24(4):385-396.

37. Yu R, Ho SC. Psychometric evaluation of the Perceived Stress Scale in early postmenopausal Chinese Women. Psychology. 2010;1(1):1-8.

38. Block J, Kremen AM. IQ and ego-resiliency: conceptual and empirical connections and separateness. J Pers Soc Psychol. 1996;70(2):349-361.

39. Yx L, Zhang L. The mental health of nurses: analysis based on journal of Chinese nursing document. J Henan Univ. 2009;28:84-87.

40. Hou JT, Wen ZL, Cheng ZJ. Structural Equation Modeling and Its Application. 2th ed. Beijing, China: Educational Science Publishing House; 2004.

41. Liu Y, Zhou MJ, Wang L, Xs L, Zhang JX. Effect of empathy, forgiveness on urban residents' life satisfaction. Chin J Behav Med Brain Sci. 2013;22:633-635.

42. Doolittle B, Courtney M, Jasien J. Satisfaction with life, coping, and spirituality among urban families. J Prim Care Community Health. 2015;6(4):256-259.

43. Gouveia VV, Milfont TL, da Fonseca PN, Coelho Japdem. Life satisfaction in Brazil: testing the psychometric properties of the Satisfaction With Life Scale (SWLS) in five Brazilian samples. Soc Indic Res. 2009;90(2):267-277.

44. Yang F, Gu D, Mitnitski A. Frailty and life satisfaction in Shanghai older adults: the roles of age and social vulnerability. Arch Gerontol Geriatr. 2016;67:68-73.

45. Daig I, Herschbach P, Lehmann A, Knoll N, Decker O. Gender and age differences in domain-specific life satisfaction and the impact of depressive and anxiety symptoms: a general population survey from Germany. Qual Life Res. 2009;18(6):669-678.

46. Cheng ST. Age and subjective well-being revisited: a discrepancy perspective. Psychol Aging. 2004;19(3):409-415.

47. Deng Y, Paul DR. The Relationships between depressive symptoms, functional health status, physical activity, and the availability of recreational facilities: a rural-urban comparison in middle-aged and older Chinese adults. Int J Behav Med. 2018;25(3):322-330.

48. Walsh JL, Ward LM. Magazine reading and involvement and young adults' sexual health knowledge, efficacy, and behaviors. J Sex Res. 2010;47(4):285-300.

49. Sameroff AJ, Mackenzie MJ. Research strategies for capturing transactional models of development: the limits of the possible. Dev Psychopathol. 2003;15(3):613-640.

50. Gao L, Zhang L, Qi H, Petridis L. Middle-aged female depression in perimenopausal period and square dance intervention. Psychiatr Danub. 2016;28(4):372-378

51. Johnston MC, Porteous T, Crilly MA, et al. Physical disease and resilient outcomes: a systematic review of resilience definitions and study methods. Psychosomatics. 2015;56(2):168-180.

52. Rutten BP, Hammels C, Geschwind N, et al. Resilience in mental health: linking psychological and neurobiological perspectives. Acta Psychiatr Scand. 2013;128(1):3-20. 
53. Luthans F, Avolio BJ, Avey JB, Norman SM. Positive psychological capital: measurement and relationship with performance and satisfaction. Pers Psychol. 2007;60(3):541-572.

54. Wu G, Feder A, Cohen H, et al. Understanding resilience. Front Behav Neurosci. 2013;7:10.

55. Schmidt M, Haglund K. Debrief in emergency departments to improve compassion fatigue and promote resiliency. J Trauma Nurs. 2017;24(5):317-322.
56. Jha AP, Morrison AB, Parker SC, Stanley EA. Practice is protective: mindfulness training promotes cognitive resilience in high-stress cohorts. Mindfulness. 2017;8(1):46-58.

57. Crane MF, Searle BJ. Building resilience through exposure to stressors: the effects of challenges versus hindrances. J Occup Health Psychol. 2016;21(4):468-479.
Psychology Research and Behavior Management

\section{Publish your work in this journal}

Psychology Research and Behavior Management is an international, peerreviewed, open access journal focusing on the science of psychology and its application in behavior management to develop improved outcomes in the clinical, educational, sports and business arenas. Specific topics covered in the journal include: Neuroscience, memory and decision making; Behavio
Submit your manuscript here: https://www.dovepress.com/psychology-research-and-behavior-management-journal

\section{Dovepress}

modification and management; Clinical applications; Business and sports performance management; Social and developmental studies; Animal studies. The manuscript management system is completely online and includes a very quick and fair peer-review system, which is all easy to use. Visit http://www. dovepress.com/testimonials.php to read real quotes from published authors. 